\title{
Duties to Endangered Species
}

\author{
An adequate ethic for preserving species requires an \\ unprecedented mix of biological science and ethics
}

\author{
Holmes Rolston III
}

I $\mathrm{n}$ the Endangered Species Act, Congress has lamented the lack of "adequate concern [for] and conservation [of]" species (US Congress 1973). But neither scientists nor ethicists have fully realized how developing this concern requires an unprecedented mix of biology and ethics. What logic underlies duties involving forms of life? Looking to the past for help, one searches in vain through 3000 years of philosophy (back at least to Noah!) for any serious reference to endangered species. Among present theories of justice, Harvard philosopher John Rawls (1971, p. 512 ) asserts, "The destruction of a whole species can be a great evil," but also admits that in his theory "no account is given of right conduct in regard to animals and the rest of nature." Meanwhile, there is an urgency to the issue. The Global 2000 Report (1980-1981) projects a massive loss of species, up to $20 \%$ within a few decades.

\section{Duties to persons concerning species}

The usual way to approach a concern for species is to say that there are no duties directly to endangered species,

Holmes Rolston III is a professor of philosophy at Colorado State University, Fort Collins, $\mathrm{CO} 80523$. He is the associate editor of the journal Environmental Ethics and author of Philosophy Gone Wild, a collection of essays in environmental ethics, to be published by Prometheus Books in spring 1986. (c) 1985 American Institute of Biological Sciences.

\section{Destroying species is like tearing pages out of an unread book, written in a language humans hardly know how to read}

only duties to other persons concerning species. From a utilitarian standpoint (Hampshire 1972, pp. 3-4), the protection of nature and "the preservation of species are to be aimed at and commended only in so far as human beings are, or will be, emotionally and sentimentally interested." In an account based on rights, Feinberg $(1974$, p. 56$)$ reaches a similar conclusion. "We do have duties to protect threatened species, not duties to the species themselves as such, but rather duties to future human beings." Using traditional ethics to confront the novel threat of extinctions, we can reapply familiar duties to persons and see whether this is convincing. This line of argument can be impressive but seems to leave deeper obligations untouched.

Persons have a strong duty not to harm others and a weaker, though important, duty to help others. Arguing the threat of harm, the Ehrlichs (1981) maintain, in a blunt metaphor, that species are rivets in the Earthship in which humans are flying. Extinctions are maleficent rivet popping. In this model, nonrivet species, if there are any, would have no value; humans desire only the diversity that prevents a crash. The care is not for particular species but, in a variant metaphor, for the sinking ark (Myers 1979a). To worry about a sinking ark seems a strange twist on the Noah story. Noah built the ark to preserve each species. In the Ehrlich/Myers account, the species-rivets are preserved to keep the ark from sinking! The reversed justification is revealing.

On the benefits side, species that are not rivets may prove to be resources. Thomas Eisner testified to Congress that only two percent of the flowering plants have been tested for alkaloids, which often have medical value (US Congress 1982, p. 296). A National Science Foundation report (1977) advocated saving the Devil's Hole pupfish, Cyprinodon diabolis, because it thrives in extremes and "can serve as useful biological models for future research on the human kidney - and on survival in a seemingly hostile environment." Myers (1979b) further urges "conserving our global stock." At first, this advice seems wise, yet later somewhat demeaning for humans to regard all other species as stock.

Destroying species is like tearing pages out of an unread book, written in a language humans hardly know how to read, about the place where they live. No sensible person would destroy the Rosetta Stone, and no self-respecting persons will destroy the mouse lemur, endangered in Madagascar and thought to be the nearest modern animal to the relatively unspecialized primates from which the 


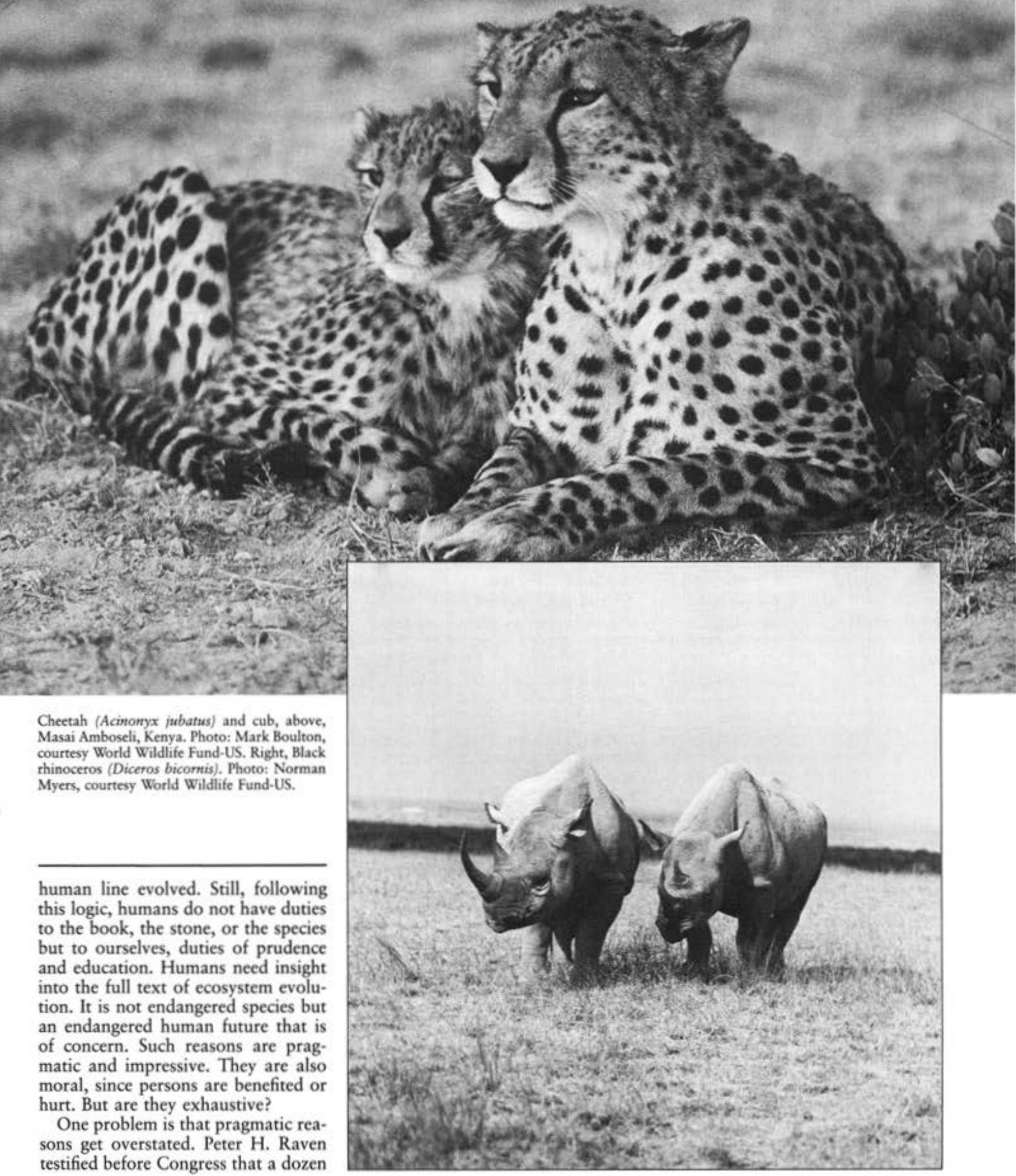


dependent species of insects, animals, or other plants typically become extinct with each plant that goes extinct (US Congress 1982, p. 293). But Raven knows that such cascading, disastrous extinction is true only on statistical average, since a plant named for him, Raven's manzanita, Arctostaphylos bookeri ssp. ravenii, is known from a single wild specimen, and its extinction is unlikely to trigger others. Rare species add some backup resilience. Still, if all 79 plants on the endangered species list disappeared, it is doubtful that the regional ecosystems involved would measurably shift their stability. Few cases can be cited where the removal of a rare species damaged an ecosystem.

Let's be frank. A substantial number of endangered species have no resource value. Beggar's ticks, Bidens spp., with their stick-tight seeds, are a common nuisance through much of the United States. One species, tidal shore beggar's tick, B. bidentoides, which differs little in appearance from the others, is endangered. It seems unlikely to be a potential resource. As far as humans are concerned, its extinction might be good riddance.

We might say that humans ought to preserve for themselves an environment adequate to match their capacity to wonder. But this is to value the experience of wonder, rather than the objects of wonder. Valuing merely the experience seems to commit a fallacy of misplaced wonder, for speciation is itself among the wonderful things on Earth. Valuing speciation directly, however, seems to attach value to the evolutionary process, not merely to subjective experiences that arise when humans reflect over it.

We might say that humans of decent character will refrain from needless destruction of all kinds, including destruction of species. Vandals destroying art objects do not so much hurt statues as cheapen their own character. But is the American shame at destroying the passenger pigeon only a matter of self-respect? Or is it shame at our ignorant insensitivity to a form of life that (unlike a statue) had an intrinsic value that placed some claim on us?

The deeper problem with the anthropocentric rationale, beyond overstatement, is that its justifications are submoral and fundamentally exploit- ive, even if subtly. This is not true intraspecifically among humans, when out of a sense of duty an individual defers to the values of fellows. But it is true interspecifically, since Homo sapiens treats all other species as rivets, resources, study materials, or entertainments. Ethics has always been about partners with entwined destinies. But it has never been very convincing when pleaded as enlightened self-interest (that one ought always to do what is one's intelligent self-interest), including class self-interest, even though in practice genuinely altruistic ethics often needs to be reinforced by self-interest. To value all other species only for human inter-

\section{The challenge now is to learn interspecific altruism}

ests is like a nation's arguing all its foreign policy in terms of national interest. Neither seems fully moral.

Perhaps an exploiting attitude, and the tendency to justify it ethically, has been naturally selected in Homo sapiens, at least in the population that has become dominant in the West. But humans-scientists who have learned to be disinterested and ethicists who have learned to consider the interests of others-ought to be able to see further. Humans have learned some intraspecific altruism. The challenge now is to learn interspecific altruism. Utilitarian reasons for saving species may be good ones, necessary for policy. But can we not also discover the best reasons, the full extent of human duties? Dealing with a problem correctly requires an appropriate way of thinking about it. What is offensive in the impending extinctions is not merely the loss of rivets and resources, but the maelstrom of killing and insensitivity to forms of life and the forces producing them. What is required is not prudence but principled responsibility to the biospheric Earth.

\section{Specific forms of life}

There are many barriers to thinking of duties to species, however, and scientific ones precede ethical ones. It is difficult enough to argue from the fact that a species exists to the value judgment that a species ought to exist-what philosophers call an argument from is to ought. Matters grow worse if the concept of species is rotten to begin with. Perhaps the concept is arbitrary and conventional, a mapping device that is only theoretical. Perhaps it is unsatisfactory theoretically in an evolutionary ecosystem. Perhaps species do not exist. Duties to them would be as imaginary as duties to contour lines or to lines of latitude and longitude. Is there enough factual reality in species to base duty there?

Betula lenta uber, round-leaf birch, is known from only two locations on nearby Virginia creeks and differs from the common B. lenta only in having rounded leaf tips. For 30 years it was described as a subspecies or merely a mutation. But M. L. Fernald pronounced it a species, B. uber, and for 40 years it has been considered one. High fences have been built around all known specimens. If a greater botanist were to redesignate it a subspecies, would this change in alleged facts affect our alleged duties? Ornithologists recently reassessed an endangered species, the Mexican duck, Anas diazi, and lumped it with the common mallard, $A$. platyrhynchos, as subspecies diazi. US Fish and Wildlife authorities took it off the endangered species list partly as a result. Did a duty cease? Was there never one at all?

If a species is only a category, or class, boundary lines may be arbitrarily drawn. Darwin (1968 [1859], p. 108) wrote, "I look at the term species, as one arbitrarily given for the sake of convenience to a set of individuals closely resembling each other." Some natural properties are used to delimit species-reproductive structures, bones, teeth. But which properties are selected and where the lines are drawn vary with taxonomists. When A. J. Shaw (1981) recently "discovered" a new species of moss, Pohlia tundrae, in the alpine Rocky Mountains, he did not find any hitherto unknown plants; he just regrouped herbarium material that had been known for decades under other names. Indeed, biologists routinely put after a species the name of 
the "author" who, they say, "erected" the taxon.

Individual organisms exist, but if species are merely classes, they are inventions. A. B. Shaw (1969) claims, "The species concept is entirely subjective," and, concluding a presidential address to paleontologists, even exclaims, "Help stamp out species!" He refers, of course, to the artifacts of taxonomists, not to living organisms. But if species do not exist except embedded in a theory in the minds of classifiers, it is hard to see how there can be duties to save them. No one proposes duties to genera, families, orders, or phyla; everyone concedes that these do not exist in nature.

But a biological species is not just a class. A species is a living historical form (Latin species), propagated in individual organisms, that flows dynamically over generations. Simpson (1961, p. 153) concludes, "An evolutionary species is a lineage (an ancestral-descendant sequence of populations) evolving separately from others and with its own unitary evolutionary role and tendencies." Mayr (1969a, p. 26) holds, "Species are groups of interbreeding natural populations that are reproductively isolated from other such groups." $\mathrm{He}$ (1969b) can even emphasize, though many biologists today would deny this, that "species are the real units of evolution, they are the entities which specialize, which become adapted, or which shift their adaptation." Recently, Mayr (1982) has sympathized with Ghiselin (1974) and Hull (1976), who hold that species are integrated individuals, and species names proper names, with organisms related to their species as part is to whole. Eldredge and Cracraft (1980, p. 92) find that "a species is a diagnosable cluster of individuals within which there is a parental pattern of ancestry and descent, beyond which there is not, and which exhibits a pattern of phylogenetic ancestry and descent among units of like kind." Species, they insist, are "discrete entities in time as well as space."

It is admittedly difficult to pinpoint precisely what a species is, and there may be no single, quintessential way to define species; a polythetic or polytypic gestalt of features may be required. All we need for this discussion, however, is that species be

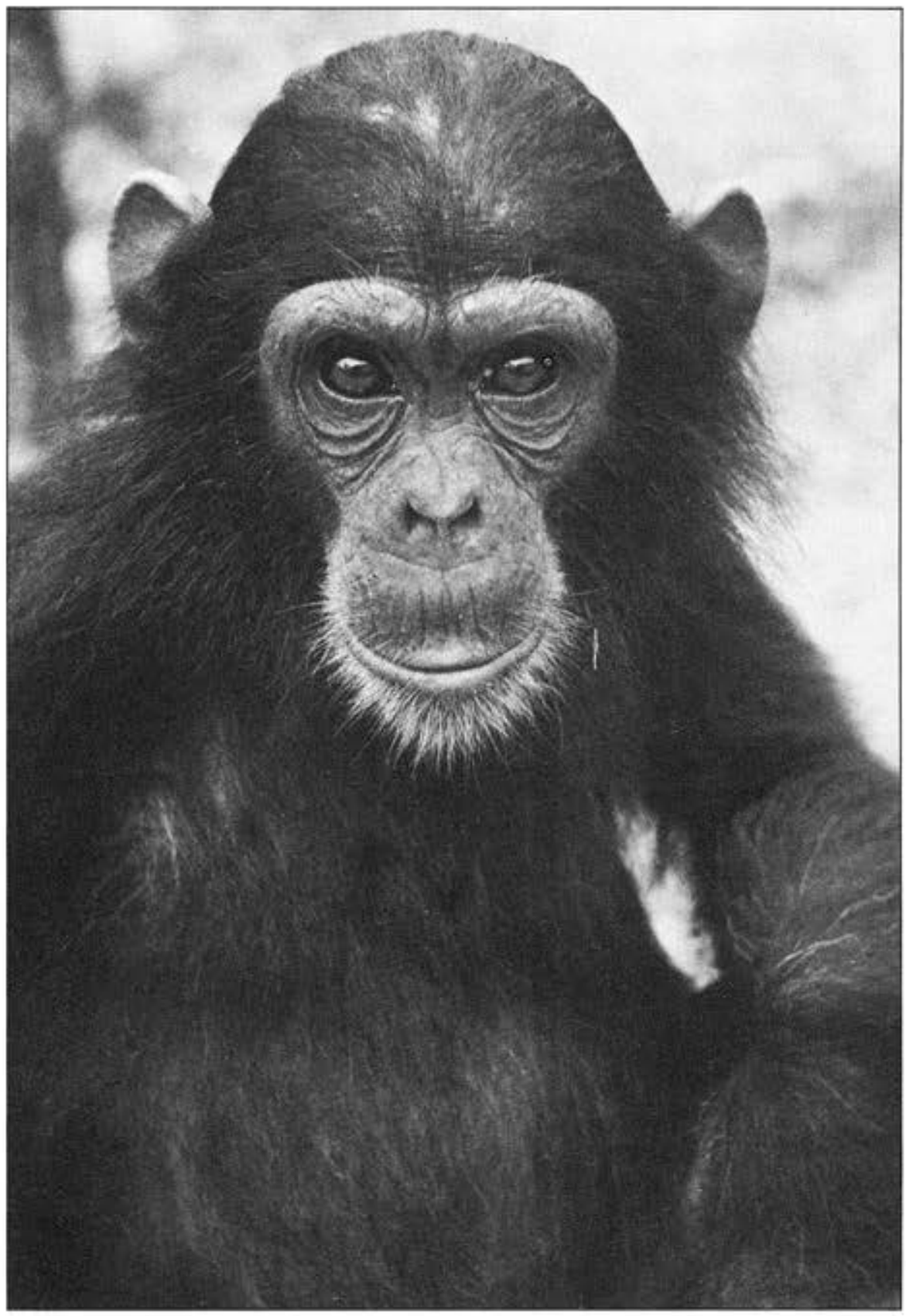

Chimpanzee (Pan troglodytes). Photo: G. Teleki, courtesy World Wildlife Fund-US.

objectively there as living processes in the evolutionary ecosystem; the varied criteria for defining them (descent, reproductive isolation, morphology, gene pool) come together at least in providing evidence that species are really there. In this sense, species are dynamic natural kinds, if not corporate individuals. A species is a coherent, ongoing form of life expressed in organisms, encoded in gene flow, and shaped by the environment.

The claim that there are specific forms of life historically maintained in their environments over time does not seem arbitrary or fictitious at all but, rather, as certain as anything else we believe about the empirical world, even though at times scientists revise the theories and taxa with which they map these forms. Species are not so much like lines of latitude and longitude as like mountains and rivers, phenomena objectively there to be mapped. The edges of all these natural kinds will sometimes be fuzzy, to some extent discretionary. We can expect that one species will slide into another over evolutionary time. But it does not follow from the fact that 
speciation is sometimes in progress that species are merely made up, instead of found as evolutionary lines articulated into diverse forms, each with its more or less distinct integrity, breeding population, gene pool, and role in its ecosystem.

At this point, we can anticipate how there can be duties to species. What humans ought to respect are dynamic life forms preserved in historical lines, vital informational processes that persist genetically over millions of years, overleaping shortlived individuals. It is not form (species) as mere morphology, but the formative (speciating) process that humans ought to preserve, although the process cannot be preserved without its products. Neither should humans want to protect the labels they use, but the living process in the environment. Endangered "species" is a convenient and realistic way of tagging this process, but protection can be interpreted (as the Endangered Species Act permits) in terms of subspecies, variety, or other taxa or categories that point out the diverse forms of life.

\section{Duties to species}

The easiest conclusion to reach from prevailing theories of justice, which involve tacit or explicit "contracts" between persons, is that duties and rights are reciprocal. But reciprocally claiming, recognizing, exercising, and enjoying rights and duties can only be done by reflective rational agents. Humans have entered no contract with other species; certainly they have not with us. There is no ecological contract parallel to the social contract; all the capacities for deliberate interaction so common in culture vanish in nature. Individual animals and plants, to say nothing of species, cannot be reasoned with, blamed, or educated into the prevailing contract.

But to make rights and duties reciprocal supposes that only moral agents count in the ethical calculus. Duties exist as well to those persons who cannot argue back-to the mute and powerless-and perhaps this principle extends to other forms of life. Morality is needed wherever the vulnerable must be protected from the powerful.

The next easiest conclusion to reach, either from rights-based or utilitarian theories, is that humans have duties wherever there are psychological interests involving the capacity for experience. That moves a minimal criterion for duty past rational moral agency to sentience. The question is not whether animals can reciprocate the contract but whether they can suffer. Singer (1979) thinks that the only reason to be concerned about endangered species is the interests of humans and other sentient animals at stake in their loss. Only they can enjoy benefits or suffer harm, so only they can be treated justly or unjustly.

But species, not sentience, generate

\section{Humans ought to respect the lifelines within species that persist genetically over millions of years}

some duties. On San Clemente Island, the US Fish and Wildlife Service and the California Department of Fish and Game asked the Navy to shoot 2000 feral goats to save three endangered plant species, Malacothamnus clementinus, Castilleja grisea, and Delphinium kinkiense. That would kill several goats for each known surviving plant. (Happily, the Fund for Animals rescued most of the goats; unhappily, they could not trap them all and the issue is unresolved.) The National Park Service did kill hundreds of rabbits on Santa Barbara Island to protect a few plants of Dudleya traskiae, once thought extinct and curiously called the Santa Barbara live-forever. Hundreds of elk starve in Yellowstone National Park each year, and the Park Service is not alarmed, but the starving of an equal number of grizzly bears, which would involve about the same suffering in psychological experience, would be of great concern.

A rather difficult claim to make under contemporary ethical theory is that duty can arise toward any living organism. Such duties, if they exist, could be easy to override, but by this account humans would have at least a minimal duty not to disrupt living beings without justification.

Here the question about species, beyond individuals, is both revealing and challenging because it offers a biologically based counterexample to the focus on individuals-typically sentient and usually persons-so characteristic in Western ethics. In an evolutionary ecosystem, it is not mere individuality that counts, but the species is also significant because it is a dynamic life form maintained over time by an informed genetic flow. The individual represents (re-presents) a species in each new generation. It is a token of a type, and the type is more important than the token.

It is as logical to say that the individual is the species' way of propagating itself as to say that the embryo or egg is the individual's way of propagating itself. We can think of the cognitive processing as taking place not merely in the individual but in the gene pool. Genetically, though not neurally, a species over generations "learns" (discovers) pathways previously unknown. A form of life reforms itself, tracks its environment, and sometimes passes over to a new species. There is a specific groping for a valued ought-to-be beyond what now is in any individual. Though species are not moral agents, a biological identity - a kind of value - is here defended. The dignity resides in the dynamic form; the individual inherits this, instantiates it, and passes it on. To borrow a metaphor from physics, life is both a particle (the individual) and a wave (the specific form).

A species lacks moral agency, reflective self-awareness, sentience, or organic individuality. So we may be tempted to say that specific-level processes cannot count morally. But each ongoing species defends a form of life, and these are on the whole good things, arising in a process out of which humans have evolved. All ethicists say that in Homo sapiens one species has appeared that not only exists but ought to exist. But why say this exclusively of a late-coming, highly developed form? Why not extend this duty more broadly to the other species (though perhaps not with equal intensity over them all, in view of varied levels of development)? These kinds defend their forms of life, too. Only the human species contains 
moral agents, but perhaps conscience ought not be used to exempt every other form of life from consideration, with the resulting paradox that the single moral species acts only in its collective self-interest toward all the rest.

Extinction shuts down the generative processes. The wrong that humans are doing, or allowing to happen through carelessness, is stopping the historical flow in which the vitality of life is laid. Every extinction is an incremental decay in stopping life processes-no small thing. Every extinction is a kind of superkilling. It kills forms (species), beyond individuals. It kills "essences" beyond "existences," the "soul" as well as the "body." It kills collectively, not just distributively. It is not merely the loss of potential human information that is tragic, but the loss of biological information, present independently of instrumental human uses for it.

"Ought species $x$ to exist?" is a single increment in the collective question, "Ought life on Earth to exist?" The answer to the question about one species is not always the same as the answer to the bigger question, but since life on Earth is an aggregate of many species, the two are sufficiently related that the burden of proof lies with those who wish deliberately to extinguish a species and simultaneously to care for life on Earth. To kill a species is to shut down a unique story; and, although all specific stories must eventually end, we seldom want unnatural ends. Humans ought not to play the role of murderers. The duty to species can be overridden, for example with pests or disease organisms. But a prima facie duty stands nevertheless.

One form of life has never endangered so many others. Never before has this level of question-superkilling by a superkiller-been faced. Humans have more understanding than ever of the speciating processes, more predictive power to foresee the intended and unintended results of their actions, and more power to reverse the undesirable consequences. The duties that such power and vision generate no longer attach simply to individuals or persons but are emerging duties to specific forms of life. If, in this world of uncertain moral convictions, it makes any sense to claim that one ought not to kill individuals without justification, it makes more sense to claim that one ought not to superkill the species, without superjustification.

\section{Individuals and species}

Many will be uncomfortable with this claim because their ethical theory does not allow duty to a collection. Feinberg (1974, p. 55) writes, "A whole collection, as such, cannot have beliefs, expectations, wants, or desires. ... Individual elephants can have interests, but the species elephant cannot." Singer (1979, p. 203) asserts, "Species as such are not con-

\section{The appropriate survival unit is the appropriate unit of moral concern}

scious entities and so do not have interests above and beyond the interests of the individual animals that are members of the species." Regan (1983, p. 359) maintains, "The rights view is a view about the moral rights of individuals. Species are not individuals, and the rights view does not recognize the moral rights of species to anything, including survival." Rescher (1980, p. 83) says, "Moral obligation is thus always interest-oriented. But only individuals can be said to have interests; one only has moral obligations to particular individuals or particular groups thereof. Accordingly, the duty to save a species is not a matter of moral duty toward it, because moral duties are only oriented to individuals. A species as such is the wrong sort of target for a moral obligation."

Even those who recognize that organisms, nonsentient as well as sentient, can be benefited or harmed may see the good of a species as the sum of and reducible to the goods of individuals. The species is well off when and because its members are; species wellbeing is just aggregated individual well-being. The "interests of a species" constitute only a convenient device, something like a center of gravity in physics, for speaking of an aggregated focus of many contributing individual member units.
But duties to a species are not duties to a class or category, not to an aggregation of sentient interests, but to a lifeline. An ethic about species needs to see how the species is a bigger event than individual interests or sentience. Making this clearer can support the conviction that a species ought to continue.

Events can be good for the wellbeing of the species, considered collectively, although they are harmful if considered as distributed to individuals. This is one way to interpret what is often called genetic load (Fraser 1962), genes that somewhat reduce health, efficiency, or fertility in most individuals but introduce enough variation to permit improving the specific form. Less variation and better repetition in reproduction would, on average, benefit more individuals in any one next generation, since individuals would have less "load." But on a longer view, variation can confer stability in a changing world. A greater experimenting with individuals, although this typically makes individuals less fit and is a disadvantage from that perspective, benefits rare, lucky individuals selected in each generation, with a resulting improvement in the species. Most individuals in any particular generation carry some (usually slightly) detrimental genes, but the variation is good for the species. Note that this does not imply species selection; selection perhaps operates only on individuals. But it does mean that we can distinguish between the goods of individuals and the larger good of the species.

Predation on individual elk conserves and improves the species $\mathrm{Cer}$ vus canadensis. A forest fire harms individual aspen trees, but it helps Populus tremuloides because fire restarts forest succession, without which the species would go extinct. Even the individuals that escape demise from external sources die of old age; their deaths, always to the disadvantage of those individuals, are a necessity for the species. A finite lifespan makes room for those replacements that enable development to occur, allowing the population to improve in fitness or adapt to a shifting environment. Without the "flawed" reproduction that permits variation, without a surplus of young 
or predation and death, which all harm individuals, the species would soon go extinct in a changing environment, as all environments eventually are. The individual is a receptacle of the form, and the receptacles are broken while the form survives; but the form cannot otherwise survive.

When a biologist remarks that a breeding population of a rare species is dangerously low, what is the danger to? Individual members? Rather, the remark seems to imply a specificlevel, point-of-no-return threat to the continuing of that form of life. No individual crosses the extinction threshold; the species does.

Reproduction is typically assumed to be a need of individuals, but since any particular individual can flourish somatically without reproducing at all, indeed may be put through duress and risk or spend much energy reproducing, by another logic we can interpret reproduction as the species keeping up its own kind by reenacting itself again and again, individual after individual. In this sense a female grizzly does not bear cubs to be healthy herself, any. more than a woman needs children to be healthy. Rather, her cubs are Ursus arctos, threatened by nonbeing, recreating itself by continuous performance. A species in reproduction defends its own kind from other species, and this seems to be some form of "caring."

Biologists have often and understandably focused on individuals, and some recent trends interpret biologi$\mathrm{cal}$ processes from the perspective of genes. A consideration of species reminds us that many events can be interpreted at this level too. An organism runs a directed course through the environment, taking in materials, using them resourcefully, discharging wastes. But this single, directed course is part of a bigger picture in which a species via individuals maintains its course over longer spans of time. Thinking this way, the life the individual has is something passing through the individual as much as something it intrinsically possesses. The individual is subordinate to the species, not the other way around. The genetic set, in which is coded the telos, is as evidently a "property" of the species as of the individual.

Biologists and linguists have learned to accept the concept of infor- mation in the genetic set without any subject who speaks or understands. Can ethicists learn to accept value in, and duty to, an informed process in which centered individuality or sentience is absent? Here events can be significant at the specific level, an additional consideration to whether they are beneficial to individuals. The species-in-environment is an interactive complex, a selective system where individuals are pawns on a chessboard. When human conduct endangers these specific games of life, duties may appear.

A species has no self. It is not a bounded singular. Each organism has its own centeredness, but there is no specific analogue to the nervous hookups or circulatory flows that characterize the organism. But, like the market in economics, an organized system does not have to have a controlling center to have identity. Having a biological identity reasserted genetically over time is as true of the species as of the individual. Individuals come and go; the marks of the species collectively remain much longer.

A consideration of species strains any ethic focused on individuals, much less on sentience or persons. But the result can be a biologically sounder ethic, though it revises what was formerly thought logically permissible or ethically binding. The species line is fundamental. It is more important to protect this integrity than to protect individuals. Defending a form of life, resisting death, regeneration that maintains a normative identity over time-all this is as true of species as of individuals. So what prevents duties arising at that level? The appropriate survival unit is the appropriate level of moral concern.

\section{Species and ecosystem}

A species is what it is inseparably from its environment. The species defends its kind against the world, but at the same time interacts with its environment, functions in the ecosystem, and is supported and shaped by it. The species and the community are complementary processes in synthesis, somewhat parallel to but a level above the way the species and the individual have distinguishable but entwined identities. Neither the individual nor the species stands alone; both are embedded in a system. It is not preservation of species but of species in the system that we desire. It is not just what they are but where they are that we must value correctly.

The species can only be preserved in situ; the species ought to be preserved in situ. Zoos and botanical gardens can lock up a collection of individuals, but they cannot begin to simulate the ongoing dynamism of gene flow under the selection pressures in a wild biome. The full integrity of the species must be integrated into the ecosystem. Ex situ preservation, while it may save resources and souvenirs, does not preserve the generative process intact. Again, the appropriate survival unit is the appropriate level of moral concern.

It might seem that ending the history of a species now and again is not far out of line with the routines of the universe. But artificial extinction, caused by human encroachments, is radically different from natural extinction. Relevant differences make the two as morally distinct as death by natural causes is from murder. Though harmful to a species, extinction in nature is no evil in the system; it is rather the key to tomorrow. Such extinction is a normal turnover in ongoing speciation.

Anthropogenic extinction has nothing to do with evolutionary speciation. Hundreds of thousands of species will perish because of culturally altered environments radically differing from the spontaneous environments in which such species were naturally selected and in which they sometimes go extinct. In natural extinctions, nature takes away life when it has become unfit in habitat, or when the habitat alters, and supplies other life in its place. Artificial extinction shuts down tomorrow because it shuts down speciation. Natural extinction typically occurs with transformation, either of the extinct line or related or competing lines. Artificial extinction is without issue. One opens doors; the other closes them. Humans generate and regenerate nothing; they only dead-end these lines.

From this perspective, humans have no duty to preserve rare species from natural extinctions, although they might have a duty to other hu- 
mans to save such species as resources or museum pieces. Humans cannot and need not save the product without the process.

Through evolutionary time, nature has provided new species at a higher rate than the extinction rate; hence, the accumulated diversity. In one of the best documented studies of the marine fossil record, Raup and Sepkoski (1982) summarize a general increase in standing diversity (Figure 1). Regardless of differing details on land or biases in the fossil record, a graph of the increase of diversity on Earth must look something like this.

There have been four or five catastrophic extinctions, each succeeded by a recovery of previous diversity. These anomalies so deviate from the trends that many paleontologists look for extraterrestrial causes. If due to supernovae, collisions with asteroids, or oscillations of the solar system above and below the plane of the galaxy, such events are accidental to the evolutionary ecosystem. Thousands of species perished at the impingement of otherwise unrelated events. The disasters were irrelevant to the kinds of ecosystems in which such species had been selected. If the causes were more terrestrial-cyclic changes in climates or continental drift-the biological processes are still to be admired for their powers of recovery. Even interrupted by accident, they maintain and increase the numbers of species. Raup and Sepkoski further find that the normal extinction rate declines from 4.6 families per million years in the Early Cambrian to 2.0 families in recent times, even though the number of families (and species) enormously increases. This seems to mean that optimization of fitness increases through evolutionary time.

An ethicist has to be circumspect. An argument might commit what logicians call the genetic fallacy to suppose that present value depended on origins. Species judged today to have intrinsic value might have arisen anciently and anomalously from a valueless context, akin to the way life arose mysteriously from nonliving materials. But in a historical ecosystem, what a thing is differentiates poorly from the generating and sustaining matrix. The individual and the species have what value they have,

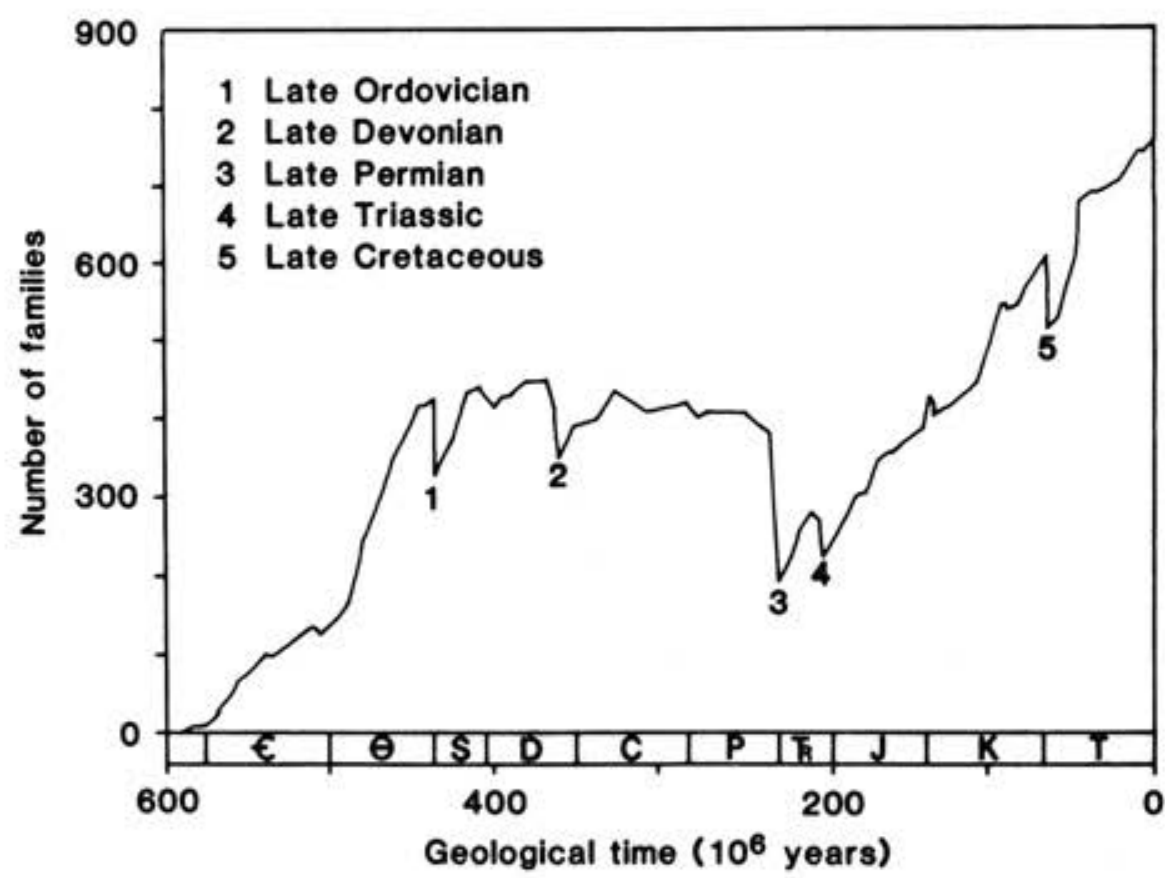

Figure 1. Standing diversity through time for families of marine vertebrates and invertebrates; numbers refer to catastrophic extinctions. Source: Raup and Sepkoski (1982). 01982 by AAAS; reprinted with permission.

to some extent, in the context of the forces that beget them.

Imagine that Figure 1 is the graph of the performance of a 600-millionyear-old business. Is it not a healthy one? But this is the record of the business of life, and the long-term performance deserves ethical respect. There is something awesome about an Earth that begins with zero and runs up toward 5 to 10 million species in several billion years, setbacks notwithstanding.

What is valuable about species is not to be isolated in them for what they are in themselves. Rather, the dynamic account evaluates species as process, product, and instrument in the larger drama toward which humans have duties, reflected in duties to species. Whittaker (1972) finds that on continental scales and for most groups, "increase of species diversity .... is a self-augmenting evolutionary process without any evident limit." There is a tendency toward "species packing." Nature seems to produce as many species as it can, not merely enough to stabilize an ecosystem or only species that can directly or indirectly serve human needs. Humans ought not to inhibit this exuberant lust for kinds. That process, along with its product, is about as near to ultimacy as humans can come in their relationship with the natural world.

Several billion years worth of creative toil, several million species of teeming life, have been handed over to the care of this late-coming species in which mind has flowered and morals have emerged. Ought not those of this sole moral species do something less self-interested than count all the produce of an evolutionary ecosystem as rivets in their spaceship, resources in their larder, laboratory materials, recreation for their ride? Such an attitude hardly seems biologically informed, much less ethically adequate. Its logic is too provincial for moral humanity. Or, in a biologist's term, it is ridiculously territorial. If true to their specific epithet, ought not Homo sapiens value this host of species as something with a claim to care in its own right?

\section{An endangered ethic?}

Contemporary ethical systems seem misfits in the role most recently demanded of them. There is something overspecialized about an ethic, held by the dominant class of Homo sapiens, that regards the welfare of only one of several million species as an 
object of duty. If this requires a paradigm change about the sorts of things to which duty can attach, so much the worse for those ethics no longer functioning in, or suited to, their changing environment. The anthropocentrism associated with them was fiction anyway. There is something Newtonian, not yet Einsteinian, besides something morally naive, about living in a reference frame where one species takes itself as absolute and values everything else relative to its utility.

\section{References cited}

Darwin, C. 1968 [1859]. The Origin of Species. Penguin Books, Harmondsworth, UK.

Ehrlich, P. R., and A. H. Ehrlich. 1981. Extinction. Random House, New York.

Eldredge, N., and J. Cracraft. 1980. Phylogenetic Patterns and the Evolutionary Process. Columbia University Press, New York.

Feinberg, J. 1974. The rights of animals and unborn generations. Pages $43-68$ in W. T. Blackstone, ed. Philosophy and Environmental Crisis. University of Georgia Press, Athens.

Fraser, G. R. 1962. Our genetical "load": a review of some aspects of genetical variation. Ann. Hum. Genet. 25: 387-415.

Ghiselin, M. T. 1974. A radical solution to the species problem. Syst. Zool. 23: 536-544.

The Global 2000 Report to the President: Entering the -Twenty-first Century. 19801981. Council on Environmental Quality and the Department of State. US Government Printing Office, Washington, DC.

Hampshire, S. 1972. Morality and Pessimism. Cambridge University Press, Cambridge, UK.

Hull, D. L. 1976. Are species really individuals? Syst. Zool. 25: 174-191.

Mayr, E. 1969a. Principles of Systematic Zool- ogy. McGraw-Hill, New York.

$1969 \mathrm{~b}$. The biological meaning of species. Biol. J. Linn. Soc. 1: 311-320.

1982. The Growth of Biological Thought. Harvard University Press, Cambridge, MA.

Myers, N. 1979a. The Sinking Ark. Pergamon Press, Oxford, UK.

$1979 \mathrm{~b}$. Conserving our global stock. Environment 21(9): 25-33.

National Science Foundation (NSF). 1977. The biology of aridity. Mosaic $8(1): 28-35$.

Raup, D. M., and J. J. Sepkoski, Jr. 1982. Mass extinctions in the marine fossil record. Science 215: 1501-1503.

Rawls, J. 1971. A Theory of Justice. Harvard University Press, Cambridge, MA.

Regan, T. 1983. The Case for Animal Rights. University of California Press, Berkeley,

Rescher, N. 1980. Unpopular Essays on Technological Progress. University of Pittsburgh, Pittsburgh, PA.

Shaw, A. B. 1969. Adam and Eve, paleontology, and the non-objective arts. J. Paleontol. 43: 1085-1098.

Shaw, A. J. 1981. Pohlia andrewsii and $P$. tundrae, two new arctic-alpine propaguliferous species from North America. Bryologist 84: $65-74$.

Simpson, G. G. 1961. Principles of Animal Taxonomy. Columbia University Press, New York.

Singer, P. 1979. Not for humans only. Pages 191-206 in K. E. Goodpaster and K. M. Sayre, eds. Ethics and Problems of the 21st Century. University of Notre Dame, Notre Dame, IN.

Whittaker, R. H. 1972. Evolution and measurement of species diversity. Taxon 21: 213-251.

US Congress, 1973. Sec. 2(a)(1) in Endangered Species Act. 87 STAT. 884 (Public Law 93205).

1982. Endangered Species Act Oversight. Hearings before the US Senate, 97th Cong., 1st sess., 8 and 10 December. 97H34. US Government Printing Office, Washington, $\mathrm{DC}$.

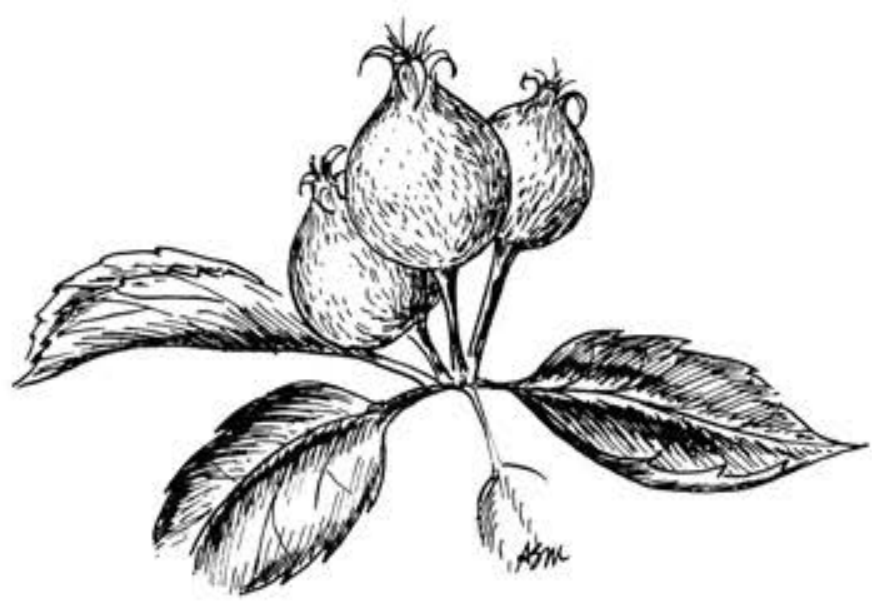

